\title{
Spiritual care in Israel: the future is now
}

\author{
Barry M Kinzbrunner ${ }^{1 *}$ and Bryan D Kinzbrunner ${ }^{2}$
}

\begin{abstract}
Spiritual care is a relatively new healthcare discipline in Israel. It has evolved over the past decade through the collaboration of multiple Israeli healthcare professionals, with assistance from interested professionals primarily from the US. The goal has been to create a spiritual care model unique to Israel. The study by Bentur et al. significantly contributes to the advancement of spiritual care in Israel by giving spiritual care providers valuable knowledge as to how the patients they care for cope with the existential and spiritual suffering of advanced illness. As the Israeli model of spiritual care is, to some degree, modeled after its counterpart in the US, this commentary compares and contrasts the two in the areas of: history, population demographics, acceptance by the healthcare system, and the available body of research. Recommendations are then presented as to how Israel, by mirroring the US experience, can create a spiritual care model that is unique to the specific needs of Israeli patients, while fostering its increased recognition as a fully integrated healthcare discipline in Israel.
\end{abstract}

On the evening of November 5 , at the Neve Ilan Hotel near Jerusalem, a group of 23 health care professionals, including nurses, social workers, and rabbis from various Jewish denominations, became the first certified spiritual care providers in Israel. This certification, granted by the Israel Spiritual Care Network at its 10th annual Spiritual Care Conference, represented an important milestone in the nascent field of Spiritual Care in Israel [1,2].

Not entirely by coincidence, one week prior to the certification ceremony, Bentur et al. submitted for publication the article entitled "Coping strategies for existential and spiritual suffering in Israeli patients with advanced cancer," which is the subject of this commentary [3]. Bentur et al.'s study evaluated the various strategies that a group of Israeli patients with advanced cancer utilized to cope with the existential and spiritual suffering that often accompanies such illnesses. Through interviews and analysis of the content, the authors were able to classify the various coping strategies used by the patients into five broad categories: openness and choosing to face reality; connectedness and the significance of family; pursuit of meaning; the connection of mind, body, and spirit; and humor and a positive outlook. They found these themes to be compatible with other studies published both in Israel [4] and abroad [5], and concluded that

\footnotetext{
* Correspondence: barry.kinzbrunner@vitas.com

'Vitas Healthcare Corporation, 201 S Biscayne Blvd, Suite 300, Miami, FL 33131, USA

Full list of author information is available at the end of the article
}

any intervention models developed to address existential and spiritual suffering should incorporate these strategies. In essence, this study, submitted in proximity to the certification of the first Israeli professional spiritual care providers and published just a few months later, gives the relatively new profession of spiritual care several important insights regarding their approach to the patients that they are both caring for now and will be encountering in the future.

One has to wonder just what that future will look like. How will the fledgling profession of spiritual care evolve in Israel and how well will it be accepted as an important component of health care, especially, but not limited to, patients with advanced cancer and others who are nearing the end of life?

\section{Spiritual care in the United States}

In order to more fully understand the dynamics of spiritual care in Israel, it is necessary to start with a brief look at spiritual care in the United States, since, as will be seen, the nascent Israeli model has, to a significant degree, used the U.S. model as a guide. (It should be noted that the authors of this commentary are utilizing the United States as a proxy for "Western Civilization" in general since there is significant sharing of knowledge between the US, Canada, and Great Britain in these areas).

Spiritual care in the United States had its beginnings in religious institutions as it was not uncommon for individuals with personal problems, which were often spiritual or 
existential in nature, to seek out their clergy for advice and counseling. With this in mind, religious leaders in the early 1900s began placing theological students in hospitals and other health care settings to provide supervised visits to patients, leading to the development of what is today known as Clinical Pastoral Education. Over time, and with integration of psychological training, the field of Pastoral Counseling developed, with the pastoral counselor receiving training in theology and other faith tradition knowledge, spirituality, resources of the faith communities, and the behavioral sciences. As the origins of Clinical Pastoral Education and Pastoral Counseling were faith based, the pastoral counselor, also known as a chaplain, were, and for the most part continue to be, clergy, although today, there are a number of health care professionals from other fields, such as psychology and social work, who are receiving sufficient clinical pastoral education to qualify as chaplains as well. In the United States today, chaplains from multiple faith backgrounds serve patients and families in hospitals, long-term care facilities, hospices, out-patient facilities, and in many communities through local religious institutions [6].

Today, the United States is an extremely diverse society. Yet, despite that diversity, a 2009 demographic survey showed that $84 \%$ of US citizens considered themselves affiliated with one of the world's major religions and more than $90 \%$ believed in the existence of God or a universal spirit, although only $60 \%$ believed in God as a being with whom people have a relationship [7]. Therefore, it is not surprising that studies evaluating the importance of spiritual issues, whether in the form of faith in God, prayer, feeling that one's life is complete, or the belief in the possibility of a miraculous recovery, demonstrate that these issues, and by extension the receipt of the spiritual care necessary to deal with them, are of significant importance to patients and their families [8-10].

Unfortunately, the physicians who care for these patients do not share their patients' views regarding the importance of spiritual care as demonstrated by a 2005 survey comparing US physicians to the general public, which showed that physicians were less likely to rely on belief in God or religion when making decisions than would the public they serve [11]. Supporting the view that these survey differences translate into the practice setting, the same studies that evaluated the importance that patients placed on spiritual issues showed that physicians virtually always found these issues of significantly less importance than their patients [8-10]. In addition, in a study evaluating how important spiritual and religious issues are to patients in medical decision-making, patients, irrespective of whether or not their spiritual or religious beliefs would influence their decision-making, indicated that they would welcome being asked about these issues as part of the medical history. Yet only $15 \%$ of patients recall ever being asked, highlighting further the gap between how US patients and their professional caregivers view spirituality and spiritual care [12].

The response to this dichotomy regarding spiritual care between patients and those who care for them consists of a two pronged strategy. First, there is an increasing body of literature being produced regarding the effects of spiritual care on health care, which demonstrate that spiritual care improves patient quality of life near the end of life [13]. Additionally, when the spiritual care interventions are provided by a trained spiritual care provider and/ or team, there is an increased impact on quality of life and can help influence patient medical-decision making toward appropriate end of life care $[13,14]$.

The second strategic initiative consists of educational efforts designed to help physicians better incorporate spiritual care into their armamentarium and to better understand how to utilize chaplains as professional spiritual care providers, to assist them in providing such care to their patients. In addition to continuing education courses in spiritual care for interested physicians and the incorporation of spiritual care training into some medical school curricula, review articles $[15,16]$ and guidelines $[17,18]$ have been and continue to be published that encourage physicians to not only better understand spiritual care, but also to learn how to assess their patients' spiritual needs, provide some spiritual support to their patients within the limits of their particular levels of expertise, and how to utilize chaplains to provide expert spiritual care to appropriate patients in need.

Regarding spiritual and existential coping strategies, the topic of the paper by Bentur et al. [3], there is a significant body of research already available defining coping mechanisms in Western society as well as studies evaluating how these strategies affect the ability of advanced cancer patients to adjust to illness $[19,20]$. This has led to the development of recommended therapeutic intervention protocols [5,21-23], with studies evaluating these interventions for effectiveness currently underway [24].

\section{Spiritual care in Israel}

One would expect that Israel, with a central rabbinate and defining itself as a Jewish state, would have a well established foundation of spiritual support in its health care system. Indeed, if one looked at the number of healthcare facilities in Israel that had rabbis on their staffs, that conclusion would seem to be supported. However, if one looked more closely, examining the job descriptions of those rabbis, one would be severely disappointed. For while the rabbis are charged with such activities as ensuring that the facility follows the Jewish dietary laws, leading prayer services in the facility, and ensuring that Jewish law is observed in other areas such as the Shabbat and medical decision-making, there is no expectation that these rabbis 
would visit patients for the purpose of providing spiritual support during their inpatient stay [25].

This is the way it would remain until about 10 years ago. Several Israeli healthcare professionals from various healthcare fields including medicine, nursing, and social work, and several interested rabbis, all had the vision to see that spiritual care would be a necessary addition to Israeli healthcare. With consultative support from the National Association of Jewish Chaplains, the organization and certifying body for Jewish chaplains based in the US, local logistic support from JDC/Eshel in Israel, and financial support from the UJA/Federation of New York, these visionary professionals initiated spiritual care training programs in several healthcare institutions. Over the ensuing decade, a yearly Spiritual Care Conference that was international in scope was established to enhance the Israeli knowledge base in spiritual care, enhance the educational and training efforts already in place, and ultimately, to create standards and requirements leading to certification as a "spiritual care provider." These efforts resulted in the certification of 23 professional "spiritual care providers" in the ceremony described at the beginning of this commentary $[1,2,25]$. It must be noted that unlike in the US, where the concept of spiritual care arose from the clergy and where the primary provider is usually a member of the clergy, in Israel, where spiritual care has arisen from a more diverse group of health care providers, "spiritual care providers," reflecting that diversity, come from a wide variety of backgrounds including social work and nursing, in addition to clergy.

The predominant religion in Israel is, of course, Judaism, with approximately $75 \%$ of the population identifying as Jewish. Of the remaining population, almost $21 \%$ are Arab (Muslim and Christian), while $4 \%$ are identified as "other" [26]. Focusing further on the Jewish population, a 2009 demographic survey showed that $46 \%$ identify themselves as secular (meaning they do not live according to Jewish law), 32\% as traditional (meaning they follow some Jewish traditions), $15 \%$ as modern orthodox, and $7 \%$ as ultra-orthodox. Despite this, the same survey showed that an overwhelming majority of Israeli Jews believe in God (80\%), that they will be rewarded for good deeds (80\%) and punished for misdeeds (74\%), and in the power of prayer (72\%) [27], suggesting that the Jewish population of Israel is much more attuned to religion and/or spirituality than indicated by the $46 \%$ who identify themselves as secular. While studies evaluating patient interest in spiritual issues and spiritual care are far less robust in Israel than in the US, one study showed that a significant minority (41\%) of a group of Israeli oncology patients being cared for in one institution expressed an interest in receiving spiritual care, while a significant majority (60\%) valued spiritual care's inclusion in the institution's services [28].
Regarding the acceptance of spiritual care by other healthcare professionals in Israel, again, there is a paucity of evidence. One study of interest, however, looked at the attitudes of Israeli oncology nurses toward spiritual care. While the investigators found that spiritual wellbeing, religiosity, and education correlated with a positive attitude toward spiritual care, it must be noted that the percentage of the nurses in the study who identified themselves as secular was higher than in the general population ( $58 \%$ v. $46 \%$ ), suggesting that, as already described regarding US physicians, there may be less emphasis on religion and spirituality among healthcare professionals than is seen in the general Israeli population [29].

It would seem, therefore, that despite having different cultures and different dominant religions, the populations of the United States and Israel are quite similar regarding their belief in a deity, the influence of spirituality on wellbeing, and the interest and importance that the population places on spiritual care. There may also be a similar dichotomy between the views of the population and of healthcare professionals on the importance of spirituality and spiritual care, although the evidence for this is speculative at best.

Returning now to the primary topic of this commentary, the paper by Bentur et al. on coping strategies for spiritual suffering [3], there is, not surprisingly, little in the Israeli health care literature with which it can be compared. As cited above, Bentur et al. commented on the similarity that the coping factors they identified had with those of an Israeli study by Blinderman and Cherny [4] that evaluated the existential issues of a group of patients seen in the outpatient oncology/palliative care clinic at a major Israeli teaching hospital. Unlike the study population in Bentur et al.'s paper, which was identified as Jewish and secular, the patients in this study were from diverse cultural and religious backgrounds closely reflecting the population of Israel, including orthodox and secular Jews, as well as several Muslims and Christians. The high degree of concordance between the factors identified in these two studies (as well as the favorable comparison with a paper describing coping factors of patients outside of Israel [5]) despite the very different populations, suggests that the coping mechanisms that patients utilize to address spiritual and existential suffering are more universal than might be realized, and might transcend specific religious beliefs or the lack thereof.

\section{The future of spiritual care in Israel}

As in the United States, education and research are keys if the spiritual care profession in Israel is to grow and flourish. Spiritual care training programs remain active and it is expected that another group of professionals will be certified at the 2015 Spiritual Care conference. Even though Israeli spiritual care providers, who at this 
time all identify as Jewish, are not necessarily members of the clergy, they currently receive training in Jewish literature and Jewish rituals. As $25 \%$ of the Israeli population is not Jewish, cross-training Jewish spiritual care providers in Muslim and Christian literature and rituals will be necessary, as will the need to recruit Muslim and Christian spiritual care providers in order to be able to serve the entire patient population [30]. It will also be important to study the nature and extent of interest in spiritual care among Muslim and Christian patients in Israel.

Spiritual care issues need to be topics of discussion at physician and nursing continuing education programs, which may have some opportunity for success with the recent recognition of Palliative Medicine as a subspecialty by the Israel Medical Association [31,32]. Training also needs to be incorporated into medical and nursing school curriculums.

Research in spiritual care needs to continue as well. As the study by Bentur et al. [3] only evaluated "secular" Israelis, it will be important to do similar studies with the segment of Jewish population that identifies itself as religious, as well on non-Jewish patients, although as discussed above, based on the comparison of the results of this study with the one by Blinderman and Chernys [4], it is likely that the results will not be very different.

Currently, spiritual care is primarily funded through grants from UJA Federation and the Joint Distribution Committee. Studies demonstrating that spiritual care in Israel are of value in improving patient quality of life and patient medical decision-making are a critical next step in order to both further the acceptance of spiritual care as an appropriate and necessary intervention, as well as to show the government and the various healthcare funds that such care should be part and parcel of the healthcare "basket of services".

Another important research topic that can be translated to the bedside would be the development of intervention protocols designed to assist the spiritual caregiver by giving them a programmatic template to follow when caring for their patients. Bentur et al. suggest that Chochinov's Dignity Therapy $[21,24]$ is such a model, and they believe that it can be adaptable to Israeli culture and society. Another model that might be of interest is Friedman's PaRDeS model, as it was developed specifically in the context of Jewish spiritual care [23], and also appears flexible enough to be useful in the care of Israeli patients who identify with other religious traditions. Finally, a third model that could be considered and is already well known within Israeli healthcare circles is Lahad's BASIC-Ph [33]. While BASIC-Ph was primarily designed to provide support and assist coping in individuals with post-traumatic stress disorder, it would also appear to be very adaptable to existential and spiritual suffering in the context of end of life care or other serious medical illnesses as demonstrated during a day-long training session that was held during the most recent Spiritual Care Conference cited at the beginning of this commentary.

However, it is important that in the context of spiritual care one does not become overly-dependent on coping strategies or therapeutic intervention models. It is vital to remember that each individual patient has his or her own unique personality, belief system, and needs. In Israel, where the Jewish population is broadly identified by its level of Jewish observance, this is especially important. When it comes to evaluating spiritual distress, it is important not to assume that a patient who identifies as "secular" will not have issues related to God or Jewish ritual (which were present in two of the case examples described in the paper by Bentur et al. despite identifying themselves as "secular"). By the same token, a patient identified as "religious" may express anger at God, or find his or her beliefs challenged when faced with a life altering event. Therefore, when providing spiritual care, it is imperative that the spiritual care professional not make assumptions based on whether the patient identifies as "secular" or "religious" or any other descriptor. The caregiver must approach each patient with a clean slate in order to understand the spiritual and existential issues being experienced by that specific individual. By taking this approach, the caregiver, primarily utilizing his or own therapeutic skills and incorporating therapeutic models such as Dignity Therapy, PaRDes, or BASIC-Ph as deemed appropriate, can develop a plan of care that will have the greatest impact on helping the individual patient deal with his or her specific issues. This is the essence of spiritual care.

Commentary on Bentur N, Stark DY, Resnizky S, Symon $\mathrm{Z}$ : Coping strategies for existential and spiritual suffering in Israeli patients with advanced cancer. Isr J Health Pol Res 2014, 3:21.

\section{Competing interests}

The authors declare that they have no competing interests.

\section{Authors' information}

Barry M. Kinzbrunner, MD, FACP, FAAHPM

Dr. Barry M. Kinzbrunner is Chief Medical Officer of Vitas Healthcare Corporation and is board certified in Internal Medicine, Medical Oncology, and Hospice and Palliative Medicine. He is an ordained orthodox rabbi and has been a voluntary consultant for JDC/Eshel in Israel for more than a decade, assisting in the development of palliative care and spiritual care services in Israel.

Rabbi Bryan D. Kinzbrunner

Rabbi Bryan Kinzbrunner is the campus chaplain for The Oscar and Ella Wilf Campus for Senior Living in Somerset, NJ. He currently serves at the

Conference Committee Chair and board member of Neshama, Association of Jewish Chaplains (NAJC).

\section{Commentary on}

Bentur N, Stark DY, Resnizky S, Symon Z: Coping strategies for existential and spiritual suffering in Israeli patients with advanced cancer. Isr J Health Pol Res 2014, 3:21. 


\section{Author details}

'Vitas Healthcare Corporation, 201 S Biscayne Blvd, Suite 300, Miami, FL 33131, USA. ${ }^{2}$ Oscar and Ella Wilf Campus for Senior Living, 350 DeMott Lane, Somerset, New Jersey 08873, USA.

Received: 27 August 2014 Accepted: 14 September 2014 Published: 29 September 2014

\section{References}

1. Ziri D: Certification awarded to first 'spiritual care provider group'. Jerusalem Post, November 7, 2013, accessed on line on August 11, 2014 at http://www.jpost.com/LandedPages/PrintArticle.aspx?id=330839.

2. Jewish Press News Briefs: First Ever Certification of Spiritual Care Providers in Israel. Jewish Press; November 11, 2013, accessed on line on August 12, 2014 at www.jewishpress.com/news/breaking-news/first-ever-certificationof-spiritual-care-providers-in-israel/2013/11/07/

3. Bentur N, Stark DY, Resnizky S, Symon Z: Coping strategies for existential and spiritual suffering in Israeli patients with advanced cancer. Isr J Health Pol Res 2014, 3:21.

4. Blinderman CD, Cherny NI: Existential issues do not necessarily result in existential suffering: lessons from cancer patients in Israel. Palliat Med 2005, 19:371.

5. Kissane DW: The relief of existential suffering. Arch Intern Med 2012, 172(19):1501.

6. American Association of Pastoral Counselors: Brief history on pastoral counseling: American Association of Pastoral Counselors: Brief history on pastoral counseling. Accessed on line on August 12, 2014 at www.aapc org/about-us/brief-history-on-pastoral-counseling/.

7. Pew Forum on Religious and Public Life: US religious landscape survey, part 2: religious beliefs and practices, social and political views, summary of key findings. 2008. Accessed 1/26/09 at http://religions. pewforum.org/reports.

8. Steinhauser KE, Christakis NA, Clipp EC, McNeilly M, Mclntyre L, Tulsky JA: Factors considered important at the end of life by patients, families, physicians, and other care providers. J Am Med Assoc 2000, 284:2476

9. Silvestri GA, Knittig S, Zoller JS, Nietert PJ: Importance of faith on medical decisions regarding cancer care. J Clin Oncol 2003, 21:1379.

10. Jacobs LM, Burns $K$, Jacobs BB: Trauma death: views of the public and trauma professionals on death and dying from injuries. Arch Surg 2008, $143: 730$.

11. Curlin FA, Lantos JD, Roach CJ, Sellergren SA, Chin MH: Religious characteristics of U.S. Physicians. A national survey. J Gen Int Med 2005, 20:629.

12. Ehman JW, Ott BB, Short TH, Ciampa RC, Hansen-Flaschen J: Do patients want their physicians to inquire about their spiritual or religious beliefs if they become gravely ill? Arch Int Med 1999, 159:1803.

13. Balboni TA, Paulk ME, Balboni MJ, Phelps AC, Loggers ET, Wright AA, Block SD, Lewis EF, Peteet JR, Prigerson HG: Provision of spiritual care to patients with advanced cancer: Associations with medical care and quality of life near death. J Clin Oncol 2010, 28:445.

14. Balboni TA, Balboni M, Enzinger AC, Gallivan K, Paulk E, Wright A, Steinhauser K, VanderWeele TJ, Prigerson HG: Provision of spiritual care to patients with advanced cancer by religious communities and associations with medical care at the end of life. JAMA Intern Med 2013, 173:1109.

15. Okun TR: Palliative care review: spiritual, religious, and existential aspects of palliative care. $J$ Palliat Med 2005, 8:392.

16. Puchalski CM: The role of spirituality in health care. Baylor U Med Cent Proc 2001, 14:352.

17. Lo B, Ruston D, Kates LW, Arnold RM, Cohen CB, Faber-Langendoen K, Pantilat SZ, Puchalski CM, Quill TR, Rabow MW, Schreiber S, Sulmasy DP, Tulsky JA: Discussing religious and spiritual issues at the end of life. A practical guide for physicians. J Am Med Assoc 2002, 287:749.

18. Puchalski C, Ferrell B, Virani R, Otis-Green S, Baird P, Bull J, Chochinov H, Handzo G, Nelson-Becker H, Prince-Paul M, Pugliese K, Sulmasy D: Improving the quality of spiritual care as a dimension of palliative care: the report of the consensus conference. J Pall Med 2009, 12(10):885.

19. Baldacchino D, Draper P: Spiritual coping strategies: a review of the nursing research literature. J Adv Nurs 2001, 34(6):833.
20. Thune-Boyle IC, Stygall JA, Keshtgar MR, Newman SP: Do religious/spiritual coping strategies affect illness adjustment in patients with cancer? A systematic review of the literature. Soc Sci Med 2006, 63:151.

21. Chochinov HM: Dignity conserving care: a new model for palliative care. J Amer Med Assoc 2002, 287:2253.

22. Chocinov HM, Hack T, Hassard T, Kristjanson L, McClement S, Harlos M: Dignity therapy: a novel psychotherapeutic intervention for patients nearing death. J Clin Oncol 2005, 23:5520.

23. Friedman DA: PaRDes: A Model for Presence in Livui Ruchani. In Jewish Pastoral Care: A Practical Handbook from Traditional and Contemporary Sources. Edited by Friedman DA. Vermont: Jewish Lights; 2005:42.

24. Chochinov HM, Kristjanson L, Breitbart W, McClement S, Hack TF, Hassard T, Harlos M: Effect of dignity therapy on distress and end-of-life experience in terminally ill patients: A randomized controlled trial. Lancet Oncol 2011, 12:753.

25. Kashouvot: Spiritual care in Israel today. Accessed on line on August 12, 2014 at www.kashouvot.org/what-is-spiritual-care/pastoral-care-in-israel/.

26. Jewish Virtual Library: Vital statistics: Latest population statistics for Israel. Accessed on line on August 18, 2014 at www.jewishvirtuallibrary.org/ jsource/Society_\&_Culture/newpop.html.

27. Arian A, Keisser-Sugarmen A, Walter D, Scheindlin D, Slepak S, Hermann T, Ventura R: A Portrait of Israeli Jews: Beliefs, Observances, and Values of Israeli Jews, 2009. Jerusalem: Israeli Democracy Institute Publications; 2012.

28. Schultz M, Lulav-Grinwald D, Bar-Sela G: Cultural differences in spiritual care: Findings of an Israeli oncologic questionnaire examining patient interest in spiritual care. BMC Palliat Care 2014, 13:19.

29. Musgrave CF, MCFarlane EA: Israeli oncology nurses' religiosity, spiritual well-being, and attitudes toward spiritual care: A path analysis. Onc Nurs Forum 2004, 31(2):321.

30. Wiener R: Chaplaincy Program Bears Fruit in Israel. New Jersey Jewish News; 2014. Accessed on line on August 11, 2014 at http://njjewishnews.com/ article/23059/chaplaincy-program-bears-fruit-in-israel.

31. Bentur N, Emanuel LL, Cherney N: Progress in palliative care in Israel: comparative mapping and next steps. Isr J Health Pol Res 2012, 1:9.

32. Bercovitch M: Budapest commitments: How palliative medicine became a subspecialty in Israel. EAPC Onlus 2013. Accessed on line on August 20, 2014 at http://eapcnet.wordpress.com/2013/04/15/budapest-commitmentshow-palliative-medicine-became-a-subspecialty-in-israel/.

33. Lahad M, Shacham M, Ayalon O: The "BASIC-Ph" Model of Coping and Resiliency. London: Jessica Kingsley Publishers; 2012.

doi:10.1186/2045-4015-3-32

Cite this article as: Kinzbrunner and Kinzbrunner: Spiritual care in Israel: the future is now. Israel Journal of Health Policy Research 2014 3:32.

\section{Submit your next manuscript to BioMed Central and take full advantage of:}

- Convenient online submission

- Thorough peer review

- No space constraints or color figure charges

- Immediate publication on acceptance

- Inclusion in PubMed, CAS, Scopus and Google Scholar

- Research which is freely available for redistribution 